\title{
HEGEMONIA E DIREITOS SOCIAIS: Como garantir o mínimo existencial e o bem comum
}

\section{Rosmar Rissi *}

\section{RESUMO}

A consagração formal dos direitos de liberdade e igualdade não garante a plenitude da satisfação dos cidadãos por parte do Estado de justiça social. O problema do presente artigo é a influência de determinadas matrizes filosóficas hegemônicas perante o mínimo existencial, seja nas políticas públicas ou nas decisões judiciais. A hegemonia exercida pelo pensamento histórico jurídico ou pelo idealismo impactam determinantemente na condução administrativa e jurídica em uma sociedade desfavorecida economicamente. A tutela do mínimo existencial, por vezes é focada no indivíduo, em detrimento do bem comum a coletividade.

Palavras-chave: Direitos sociais. Mínimo existencial. Hegemonia. Tributos. Proteção.

\section{HEGEMONY AND SOCIAL RIGHTS: How to guarantee the existential minimum and the common good}

\begin{abstract}
The formal consecration of the rights of freedom and equality does not guarantee the full satisfaction of citizens on the part of the State of social justice. The problem of the present article is the influence of certain hegemonic philosophical matrices before the existential minimum, either in public politics or in judicial decisions. The hegemony exercised by legal historical thought or idealism has a decisive impact on administrative and legal management in an economically disadvantaged society. The protection of the existential minimum is sometimes focused on the individual, to the detriment of the common good of the collectivity.
\end{abstract}

Keywords: Social rights. Existential minimum. Hegemony. Taxes. Protection.

\section{INTRODUÇÃO}

A efetivação do mínimo existência, está conectada com a noção do Estado Democrático de Direito construído a partir do preenchimento de lacunas ao longo da história, em que apontam promessas como a igualdade, justiça social e a garantia dos direitos fundamentais e sociais. (STRECK, 2013, p.150).

\footnotetext{
* Mestre em Direito pela UNISINOS, CAPES 6. Especialização em Gestão Estratégica de Pessoa e Especialização em Direito do Trabalho e Processo do Trabalho pela PUCRS. Especialização em Formação para a Vida Religiosa, pela ESTEF. Graduado em Direito, pela PUCRS. Autor de livros, entre eles (Teoria do Mínimo existencial: Direitos Fundamentais Sociais e Democracia), e com diversos artigos publicados. Advogado. Contato: rosmarrissi@gmail.com
} 
Entretanto, toda a construção estatal, emana de pensadores que idealizam no mundo das ideias, as ações que melhor dinamizam a sociedade, porém, a partir de determinados conceitos e percepções sociais da realidade onde estão inseridos.

O problema suscitado no presente artigo é, a influência de determinadas matrizes filosóficas hegemônicas perante o mínimo existencial, seja nas políticas públicas ou nas decisões judiciais emanadas, tendo em vista a melhor garantia do bem comum efetivado através do mínimo existencial.

Como hipótese, é possível considerar que não há influência das matrizes filosóficas nas decisões e nas ações do dia a dia, para a garantia do mínimo existencial. Que a estrutura estatal atua independente de hegemonias, não sendo influenciada por ela. Entretanto há que se considerar como hipótese, a significativa influência das matrizes filosóficas nas decisões judiciais e na ação governamental, a nível administrativo do dia a dia perante a sociedade

Tem-se por finalidade, investigar as matrizes filosóficas hegemônicas do historicismo e do idealismo, bem como uma breve abordagem sobre o tema bem comum abordado por Santo Tomas de Aquino, e confrontando-as com a teoria do mínimo existencial e as ações que tutelam o mesmo. Demonstrar comparativamente a influência da matriz filosófica hegemônica nas decisões que levam a garantia do bem tutelado no mínimo existencial, bem como sua eficiência e eficiência.

O presente artigo tem como perspectiva de pesquisa o método fenomenológicohermenêutico. Considerando que o método de abordagem objetiva aproxima o sujeito (pesquisador) do objeto a ser pesquisado, onde se analisa e compara o conceito do Mínimo existencial com uma matriz filosófica hegemônica, compreendidas apenas entre a histórico jurídico e a idealista. Faz parte deste contexto a ser pesquisado, um breve estudo do conceito de bem comum e, por fim, analisar-se-á a relação entre as matrizes filosóficas hegemônicas, com a tutela do mínimo existencial.

O futuro do mínimo existencial está atrelado a condução democrática e eficiência administrativa estatal. Políticas com interesses de grupos estatais organizados hegemonicamente, tanto na esfera legislativa como no judiciário, podem colocar em dúvida a eficiência do próprio Estado na garantia do mínimo existencial, e de todos os direitos sociais a quem deles necessitam.

\section{CONCEPÇÕES DE MÍNIMO EXISTENCIAL NA DOUTRINA BRASILEIRA}


A efetivação do mínimo existencial pode ocorrer através de prestações positivas por parte do Estado; ou pelas prestações negativas estatais. São ações que demandam atitude e decisão do próprio estado, para a sua real efetivação.

A difícil compreensão do mínimo existencial, deve-se a falta de expressa menção em nosso ordenamento jurídico. Para compreendê-lo é preciso adentrar as veredas da legislação e encontrar as bases que o fundamentam, porem elas estão localizadas de maneira indireta, por exemplo no direito à dignidade humana na Constituição Federal. A compreensão dos doutrinadores é diversa, bem como a sua principiologia.

\section{1 - Conceituando o conteúdo do Mínimo Existencial}

A expressão "mínimo existencial” possui significado semântico diverso daquele juridicamente considerado. Decotando a expressão nas duas palavras que a compõem e recorrendo ao vernáculo brasileiro, tem-se: mínimo como o "que é o menor; que está no grau mais baixo [...]; a menor porção ou grau de" (FERREIRA, 2004, p. 1334); existencial, como “da existência, ou referente a ela" (FERREIRA, 2004, p. 854); e, por sua vez, existência, como "o fato de existir, de viver [...], ente, ser" (FERREIRA, 2004, p. 854). Aproximando as duas palavras na expressão ora referida, pode-se concluir que, semanticamente, o "mínimo existencial" poderia ser considerado como a "menor porção da existência", no caso, da vida humana, o que poderia denotar, inclusive, um conteúdo matemático, uma vez que "porção de uma coisa" pode referir-se a algo aferível por alguma modalidade de medida quantitativa.

É simples demais o significado dado à expressão "mínimo existencial” pela língua pátria, que não coincide com aquele juridicamente considerado. Vale dizer, o núcleo do mínimo existencial vai muito além do que a justaposição gramatical revela. O mínimo existencial para o Direito possui íntima relação com a dignidade humana.

Em seu conceito, portanto, não se pode deixar de fazer referência àquele atributo inerente ao ser humano. Não há dissenso em se considerar que, juridicamente, o mínimo existencial refere-se ao "conjunto das condições materiais indispensáveis para assegurar a cada pessoa uma vida condigna”. (SARLET, 2007, p. 105).

Os requisitos básicos para a existência humana, adicionados aos elementos necessários ao exercício da sua dignidade, é que configuram o cerne do mínimo existencial. Esse compreende o conjunto de situações materiais a uma existência com dignidade, mas não somente uma existência meramente física, como também espiritual e intelectual, 
fundamentais em um Estado que, pela feição democrática, demanda a participação dos indivíduos nas gerências públicas e, pelo aspecto liberal, permite a cada um o alcance de seu próprio desenvolvimento. (BARCELLOS, 2002, p. 197-198).

Outrossim, a dignidade propriamente dita não está sujeita à aferição quantitativa, tendo em vista que a garantia efetiva de uma existência digna ultrapassa o limite da mera sobrevivência física, conforme se afirmou. A Declaração Universal dos Direitos Humanos (1948) oferece à compreensão um referencial para as condições básicas de vida humana com dignidade, dispondo em seu art. 25, I:

Todo homem tem direito a um padrão de vida capaz de assegurar a si e a sua família saúde e bem-estar, inclusive alimentação, vestuário, habitação, cuidados médicos e os serviços sociais indispensáveis, e direito à segurança em caso de desemprego, doença, invalidez, viuvez, velhice ou outros casos de perda de meios de subsistência em circunstâncias fora de seu controle. (COMPARATO, 2007, p. 234).

É importante destacar que o padrão de vida referido pelo documento supracitado, não se atém ao aspecto quantitativo, mas, qualitativo, muito embora se reconheça que os elementos propiciadores da saúde e o bem-estar, por serem materiais, dependem do fator econômico-financeiro para sua efetivação.

Na compreensão de Luiz Edson Fachin (2006, p. 271), o “mínimo" e o "máximo" não são necessariamente duas espécies do gênero “extremo". São eles "as barreiras que fixam a essência de cada coisa e delimitam o seu poder e as propriedades. $\mathrm{O}$ mínimo pode ser mais que uma quantificação reducionista ou vinculado à ideia de básico ou elementar.

Entretanto, as prestações positivas estatais, o valor destinado à garantia das condições existenciais mínimas está vinculado espacial e temporalmente ao standard socioeconômico, sujeito às flutuações não apenas nas esferas econômica e financeira, como também às expectativas e necessidades vigentes. (SARLET, 2007, p. 101).

Todavia, nas prestações negativas, não é fácil identificar as situações nas quais a ingerência estatal ultrapassa a parcela mínima de garantia de uma vida digna, já que, carregado de subjetividade, o entendimento se faz sobre um referencial mínimo de existência com dignidade, garantido pelo direito fundamental de acordo com a CF. A fixação do mínimo existencial fatalmente variará de acordo com o que se entende por vida digna, em dado 
momento histórico e em dada sociedade a qual possui suas peculiaridades culturais e econômicas, bem como o sistema de governo adotado.

Porém, o que não se pode conceber é a consideração de um mínimo que permita a espoliação da dignidade humana, frente aos seus direitos constitucionalmente previstos e fundamentalmente positivados.

Numa realidade de países pobres ou em desenvolvimento como o Brasil, a medida do mínimo existencial possui uma maior extensão que nas nações ricas, uma vez que, naqueles, há uma maior necessidade de proteção estatal aos bens considerados essenciais à vivência digna. A interpretação, portanto, das imunidades e das pretensões dos pobres às prestações sociais, deve ser extensiva. (TORRES, 2001, p. 286).

O constituinte de 1988, ao inserir no artigo $3^{\circ}$, inciso I, da Carta Constitucional que é objetivo do Estado Brasileiro constituir uma sociedade livre, justa e solidária, irradiou para o Direito Tributário a necessidade de observância de uma política fiscal que obedeça aos princípios da liberdade, justiça social e solidariedade. Vinculam-se, assim, o Direito Tributário e os Direitos Fundamentais, cuja doutrina contemporânea está consolidada a partir de uma conscientização de que a tributação existe como meio para a realização da justiça social, sendo um importante instrumento para o alcance do propósito de uma vida digna para todos (GRUPENMACHER, 2006, p. 102).

É dever constitucional do Estado não apenas o de se abster da prática de atos tentadores à dignidade humana, como também o de promover esta dignidade e a garantia de direitos por meio de condutas ativas, garantindo o mínimo existencial para cada ser humano em seu território (SARMENTO, 2002, p.71).

\section{2 - Condição para o exercício da liberdade real}

A concretização do mínimo existencial, o qual é definido e tratado neste artigo como uma regra jurídica, tem que se valer de valores, tais como a liberdade, a justiça e a solidariedade. Valores estes conhecidos desde a Revolução Francesa que possuía os ideais de liberdade, igualdade e fraternidade.

Para Kant, a justiça é uma forma da distribuição de liberdade, entretanto, na compreensão de Rawls, ocorre a separação de liberdade e justiça, sendo que a liberdade é considerada uma necessidade básica, um mínimo social, não devendo ser confundida com a justiça, mesmo em sua compreensão de justiça básica. (TORRES, 2009, p. 138). 
Na elaboração teórica de Dworkin, que aborda a relação entre liberdade e justiça, bem como a igualdade, o autor descarta a hipótese de conflito entre os valores, porque a igualdade não pode ser definida senão assumindo o lugar da liberdade, e não pode ser melhorada, mesmo no mundo real, logo, a igualdade é fundamental na definição da liberdade. (TORRES, 2009, p. 138).

Nesse contexto, o mínimo existencial é pervertido de seu curso natural de garantir o princípio da liberdade fática. Cristina Queiroz (2006, p. 49-50), enfatiza que "os direitos fundamentais sociais garantem a liberdade fática. A liberdade jurídica mostra-se sem sentido quando na realidade não pode ser exercida". Ocorre aqui a perda do objeto típico dos direitos fundamentais sociais, ou seja, a proteção em menor grau do mínimo, passando assim a uma situação de garantia de liberdade inferior ao mínimo necessário para a dignidade da vida.

A liberdade real não pode ser entendida nos termos da liberdade formal, e da liberdade positiva em oposição à liberdade negativa. Entretanto, a liberdade real não pode justificar condições de sobrevivência humana na linha da miséria, este não é o argumento justificável para a permanência no estado de injustiça social, sem condições de superação desta realidade.

\section{3 - A liberdade e a autonomia da vontade}

No conceito negativo de liberdade abordado por Kant, o qual não é produtivo, mas é a base para o conceito positivo, Kant (2009, p. 347) assim descreve o conceito negativo de liberdade: "A vontade é uma espécie de causalidade dos seres vivos, na medida em que são racionais, e liberdade seria aquela propriedade dessa causalidade, na medida em que esta pode ser eficiente, independentemente da determinação por causas alheias". No caminho para o conceito positivo de liberdade a partir da vontade, há a possibilidade de um imperativo categórico.

Diante da questão: "que outra coisa pode ser, pois, a liberdade da vontade senão autonomia e a propriedade da vontade de ser lei para si mesma?” Kant (2009, p. 349) prossegue a resposta da questão enfatizando que "a vontade é, em todas as ações, uma lei para si mesma", ou seja, a liberdade atende ao pressuposto da vontade, que sua vez não é oriunda da causalidade, mas sim da vontade e da autonomia do ser humano. 
A liberdade proposta por Kant não é única e exclusiva em sua totalidade, mas vinculada à vontade, a qual impulsiona o agir sob a ideia de liberdade e todas as leis. Para Kant (2009, p. 353), o ser pode agir a partir de uma tríade, como exemplifica: "A todo o ser racional que tem uma vontade temos que atribuir-lhe necessariamente também a ideia da liberdade, sob a qual ele unicamente pode agir". A racionalidade permite ter uma vontade, que por sua vez permite julgar o seu agir, devido à liberdade atribuída. Sendo esta vontade própria, o ser é livre para praticar a sua vontade, desde que o mínimo lhe tenha sido garantido, pois, sem isso não tem como decidir.

Kant (2009, p. 369) confronta o ser humano diante de duas realidades de mundo, o sensível e o inteligível. A racionalidade humana deve optar pelo mundo inteligível, o qual resulta em admitir dois pontos de vista, dos quais pode considerar-se a si mesmo e reconhecer leis do uso das suas forças, e, portanto, de todas as suas ações.

O primeiro, enquanto pertence ao mundo sensível, sob leis naturais (heteronomia); o segundo, como pertencente ao mundo inteligível, sob leis que, independentes da natureza, não são empíricas, mas fundadas somente na razão.

Como ser racional e, portanto, pertencente ao mundo inteligível, o homem não pode pensar nunca a causalidade da sua própria vontade senão sob a ideia da liberdade, pois que independência das causas determinantes do mundo sensível é liberdade. Ora à ideia da liberdade está inseparavelmente ligado o conceito de autonomia, e a este o princípio universal da moralidade, o qual na ideia está na base de todas as ações de seres racionais, como a lei natural está na base de todos os fenômenos. (KANT, 2009, p.371).

A tríade da liberdade, autonomia e moralidade, pode ensejar uma sequência na conduta humana. Entretanto, a liberdade é suprema, não pode ser exercida à força da moralidade, nem empregar a autonomia para atingir um fim moral. A liberdade não carrega o estigma da ideia de fundamentar a lei moral, nem sempre compreendida por este viés. Quando a liberdade compreende o ser no agir racional, a partir de sua própria concepção, ela encontra o estado de lei natural, onde as vontades predominam, bem como a felicidade. Entretanto, como Kant (2009, p. 371) enfatiza, uma parte é do mundo sensível e a outra do racional, e que neste último a moralidade predomina, através da racionalidade.

Nessa compreensão, são possíveis os imperativos categóricos uma vez que não há a prevalência de uma única ideia. Sendo somente a liberdade o ser humano poderia ser guiado pela sua autonomia da vontade, advindo a ele a satisfação de todas as vontades que desejasse. 
Entretanto, a lei no mundo da razão regula o entendimento das ações possíveis a ser adotada de acordo com à autonomia inerente a situação. (KANT, 2009, p. 375).

Mais ao final de sua obra, Rawls quebra de vez qualquer aparente rigidez na ordem de realização de seus princípios, admitindo, até mesmo, a efetivação do segundo antes do primeiro. Vale transcrever o trecho de sua teoria que confirma essa visão, a fim de se evitarem dúvidas quanto à sua interpretação:

\footnotetext{
Embora os interesses fundamentais na liberdade tenham um objetivo definido, ou seja, o estabelecimento efetivo das liberdades básicas, é possível que esses interesses nem sempre pareçam na posição de direção. A realização desses interesses pode exigir certas condições sociais e um grau de satisfação de necessidades e carências básicas, e isso explica por que a liberdade pode algumas vezes ser restringida. Mas uma vez que se atingem as condições sociais e o grau de satisfação de necessidades e carências materiais necessários, como acontece em uma sociedade bem organizada em circunstâncias favoráveis, os interesses de ordem superior passam a ser normativos. (RAWLS, 2002, p. 604).
}

O que pode ser depreendido até o momento, a partir da ordem de precedência dos princípios e de sua eventual inversão, é que, para Rawls, o primeiro princípio somente se pode realizar, se atendidas as necessidades básicas dos indivíduos. Ou seja, presumindo uma sociedade bem ordenada, como propôs o autor, a prioridade do primeiro princípio depende de terem sido satisfeitas as necessidades básicas das pessoas, através das instituições sociais. Para que os indivíduos venham a desfrutar seus direitos e liberdades, há, primeiramente, que serem atendidas certas condições básicas relativas ao bem-estar.

\section{A COMPREENSAO DE HEGEMONIA E BEM COMUM}

Tentar conceituar e definir teorias de maneira sucinta, é correr o risco de trucidar a própria teoria, onde seus autores estudiosos, por anos pesquisaram e escreveram. O ponto central desta seção é compreender o termo filosófico hegemonia, e posteriormente, identificar a sua influência no Mínimo Existencial.

Entre os escritos mais relevantes estão os do autor italiano Antônio (GRAMSCI, 2000) especialmente em "Cadernos do Cárcere", no qual "hegemonia" é definida como a capacidade de um Estado ou de um grupo social de apresentar-se como "portador de interesses gerais e de convencer os outros Estados ou grupos sociais de que os interesses que 
representa são, de fato, interesses comuns". A ênfase recai, aqui, no caráter consensual dos interesses defendidos pelo grupo social hegemônico, conquistado a partir do convencimento.

No entendimento de Coutinho, (1997) há ligação entre o conceito gramsciano de hegemonia e as reflexões da filosofia política sobre "vontade geral" e "contrato" desenvolvidas por Hegel e Rousseau. Essa articulação é central para entendermos em que medida "hegemonia" e "dominação" são relações sociais de poder. No que se refere à influência hegeliana no conceito gramsciano de "hegemonia", Coutinho destaca:

Por um lado, Gramsci recolhe de Hegel (e, naturalmente, de Marx, que, por sua vez, também bebe na fonte hegeliana) a ideia de que as vontades são determinadas já no nível dos interesses materiais e econômicos; e dele recolhe ainda a afirmação de que essas vontades passam objetivamente por um processo de universalização que leva à formação de sujeitos coletivos (as "corporações" hegelianas se tornam em Gramsci os 'aparelhos 'privados de hegemonia'). Tais sujeitos são movidos por uma vontade cada vez mais universal (ou, na terminologia gramsciana, eles superam a afirmação de interesses meramente 'econômico-corporativos' e se orientam no sentido de uma consciência "ético política"). Esse movimento de superação, ao qual Gramsci deu o sugestivo nome de 'catarse', é precisamente o que configura uma relação de hegemonia. (COUTINHO, 1997: s.p.)

A preponderância da vontade geral sobre a vontade particular resulta da correlação de forças entre as classes sociais. O consenso em torno dos objetivos defendidos por um grupo social é, nesse sentido, expressão de um sistema histórico de organização e compatibilização das relações sociais, ou, nos termos da Regulação, de um modo de regulação das relações sociais. Portanto, nos períodos em que o caráter complementar sobrepõe-se ao caráter antagônico das relações sociais, abre-se a possibilidade de formação de um modo de regulação e de consolidação de uma hegemonia. Nos períodos em que o antagonismo suplanta a complementaridade, as contradições das relações sociais tendem a aflorar, abrindo a possibilidade de crises hegemônicas.

No estudo da sociedade capitalista, Gramsci percebe um Estado maduro que se ampliou criando uma complexidade de poder, o que viabiliza uma nova categoria de análise da "sociedade civil", tornando mais complexas as formas de estruturação das classes sociais e sua relação com a política, visando à construção de uma nova sociedade que passaria, necessariamente, pela construção de uma nova hegemonia, cuja estruturação não passaria somente pelo campo econômico, mas pela estrutura da sociedade fortemente determinada por ideias e valores culturais (CERRONI, 1978). 
Para Gramsci a hegemonia como "direção intelectual e moral" quer dizer que ela também se exerce no campo das ideias e da cultura, manifestando a capacidade de conquistar o consenso e de formar uma base social, pois hegemonia "é algo que opera não apenas sobre a estrutura econômica e sobre a organização política da sociedade, mas também sobre o modo de pensar, sobre as orientações ideológicas e sobre os modos de conhecer" (GRUPPI, 1978).

Nesse sentido, é possível afirmar que para Gramsci a questão cultural traz consigo as características das esferas econômica e política, e as suas preocupações sobre as ações dos trabalhadores e as tentativas de construção da hegemonia proletária, estão inscritas numa leitura de mundo que produziu conceitos e concepções a partir da realidade prática e que, ao partir de movimentos concretos, operados por homens reais, participantes da construção da sociedade, Gramsci desenvolveu uma filosofia viva, um pensamento que, nascido de uma dada realidade social, é orgânico a ela e se consolidou mediante a superação das contradições impostas pela organização social vigente.

\section{1 - Correntes filosóficas hegemônicas}

A primeira corrente filosófica a ser investigada é a do historicismo jurídico, a qual defende que, da mesma forma que a cultura, o Direito é peculiar a cada povo e está ligado aos fatos sociais.

Os principais pensadores do historicismo jurídico são, Friedrich Puchta, Gustav Hugo e Friedrich Carl Von Savigny. Essa corrente também é conhecida por historicismo casuístico.

Não obstante, como um elo que se acede a essa corrente, mas por inspirações procedentes de um radicalismo muito maior que o de Montesquieu, houve, ainda, na Alemanha, a chamada Escola Histórica do Direito, onde todo ordenamento jurídico é algo historicamente identificado, bem como exclusivamente próprio de um determinado povo. Deste, tal ordenamento é inseparável, não estando sequer sujeito a enxertos ou transmigrações. Friedrich Carl Von Savigny, um dos maiores expoentes dessa escola, sustenta que o direito vive na prática e no costume, que é a expressão imediata da "consciência jurídica popular". Isto é devido ao fato de que todo povo tem um espírito, uma alma sua, que se reflete numa numerosa série de manifestações, de modo que: moral, direito, arte, linguagem, etc. são 
todos produtos espontâneos e imediatos desse espírito popular (GOYARD-FABRE, 1973, p. 289).

\section{2 - Idealismo}

Georg Wilhelm Friedrich Hegel, filósofo alemão, foi um dos pensadores do idealismo alemão. Sua corrente filosófica partiu da ideia da autoconsciência, para recuperar a ontologia (parte da filosofia que estuda a natureza do ser, a existência e a realidade) como a lógica do ser.

O termo Idealismo, vem do Latim tardio "IDEALIS". Em sentido comum, significa dedicação, engajamento a uma Doutrina, a uma Causa, um compromisso com um "Ideal", sem que exista interesse material ou, até mesmo, anseio pela imediata concretização daquele "Ideal". (JAPIASSÚ, 2008).

O idealismo, concepção usado por Georg Wilhelm Friedrich Hegel (1770/1831, Alemanha) para demonstrar a sua noção de Metafísica (do que está além do físico, o sobrenatural). Segundo o filósofo, o Real (ou a Realidade) “È” a IDÉIA, mas NÃO em sentido subjetivo ou individual; porém em sentido absoluto. Para Hegel tudo que está "abaixo" da Metafísica, ou seja, o material, concreto, físico é apenas uma ilusão, mas que deve ser considerada; a partir daí é que Hegel propôs uma espécie de "Monismo" onde Essência e Fenômeno formam uma única coisa. Um único ente. E como ele afirmava que o Real (ou a Realidade) é racional (isto é, pode ser atingida através da Razão), Essência e Fenômeno são, consequentemente, compreensíveis pelo Raciocínio, que constrói de ambos uma representação, uma Ideia. Por isso, o "seu" Idealismo é Absoluto. É o "Idealismo Total" que abarca tanto o interior quanto o exterior de qualquer Coisa ou Ser (JAPIASSÚ, 2008).

$\mathrm{Na}$ tradição filosófica, o Idealismo combate, é claro, as Doutrinas Materialistas na medida em que para o Idealismo o Universo é um conjunto de mínimo dois elementos ou princípios: Matéria e Pensamento. Ou de um só: o Pensamento e a matéria mera representação mental.

Atualmente, no campo do Marxismo, o "Idealismo" passou a significar algo bom, excelente, mas utópico e irrealizável. Especialmente no Campo da Moral, onde não são raras as ótimas, generosas e altruístas intenções que nunca se realizam, principalmente em razão da natureza humana (ou seja, da forma que o Homem é), que ainda rasteja no terreno da pura competição (VILELLA, 2016). 
Gramsci apontou para a questão da hegemonia e destacou a relação entre domínio e direção. Ao pensar na criação da ditadura do proletariado, afirmou que os proletários, além de se tornarem dominantes, precisariam ser dirigentes. De outro lado, indicou a necessidade de obtenção do consenso para que, com o apoio de classes aliadas, seja adquirida e mantida a governabilidade do Estado operário. A hegemonia se refere, assim, à instituição do Estado operário, mas que deve ser realizada mediante o consenso dos diferentes grupos sociais, em especial dos trabalhadores, operários das fábricas do Norte, e os camponeses do Sul. Para Gramsci, a discussão acerca da hegemonia do proletariado passava necessariamente pela questão meridional (GRUPPI, 1998).

\section{3 - O conceito abrangente de bem comum}

O conceito de bem comum, especificamente abstraído da Suma Teológica de Tomás de Aquino, neste contexto comparatista, é que ele se torna uma possibilidade real de realização de ações políticas e jurídicas em prol do mínimo existencial. Pensar estes dois termos, é perceber a possibilidade de algum ponto de cruzamento, ou da necessidade da efetivação na sociedade.

Partindo do pensamento Tomás de Aquino, destaca-se três sentidos para aplicar a noção de bem comum conforme era pensada por ele: 1) bem comum como predicado; 2) bem comum como meio; e 3) bem comum como causa e fim último. Esse primeiro sentido referese àquelas coisas que são potencialmente, e abstratamente, bens para qualquer um. São bens comuns que fazem parte da natureza humana, como a felicidade ou o conhecimento, mas não são fins em si mesmos (FROELICH, 2008, p.2).

Cabe dizer, que o bem comum está ligado à razão humana, e esta razão, ordenada ao "todo" de um universo hierarquicamente organizado. Diz Tomás: “O objetivo da vontade é o bem e o fim universal". Nesse sentido, quando o homem busca pelo bem comum, ele imita o "movimento" celestial: assim como o céu move todos os corpos inferiores tendo em vista a conservação dos mesmos, igualmente o rei, por exemplo "que tem por fim o bem comum de todo o reino" também "move por suas ordens, cada um dos governantes das cidades". Para Tomás, é "da vontade divina" que "por uma vontade racional, se alcance o bem universal" e cita Aristóteles para argumentar que "não só o intelecto, mas também a natureza age em vista do fim". Bradley Lewis define que a intenção sempre precede a ação. É nesse sentido que, 
para Tomás, todos os cidadãos, devem ter, por intenção (ou vontade) a busca pelo bem comum. O que Tomás chama de bem comum está em conformidade com a vontade divina, e por isso, é superior a todas as outras vontades humanas: o bem comum de todo o universo é o que Deus apreende, uma vez que ele é o criador e governante desse universo. (LEWIS, 2006).

Mark Murphy definiu que o cosmos, segundo a visão de Tomás, é criado e governado providencialmente pelo Ser Perfeito, e possui uma hierarquia de diversos níveis do ser: os anjos, os humanos, os animais não-racionais, os vegetais e os seres inanimados. O homem quando busca e trabalha pelo bem comum da sociedade está fazendo-o não apenas por uma ordenação divina ou por uma inclinação moral, mas mais do que isso, ele o faz por que é natural do ser que, sendo livre, faça uso da sua razão. A razão, tende à busca do bem comum da sociedade. E isso, consequentemente, fazendo uso do vocabulário de Tomás, é "natural", pois preserva a organização do mundo. Para que o universo possa atingir sua perfeição última, deve retornar a seu princípio”. (MURPHY, 1997, p. 324).

No pensamento teológico de Tomás, uma importante virtude que está constantemente associada ao exercício do bem comum é a virtude da caridade, inclusive entendida como uma virtude política, de modo que essas são fundadas "na amizade de caridade" "[as] virtudes políticas (...) levam os cidadãos a despenderem os próprios bens e pessoas, em vista do bem comum. (...) O homem deve, portanto, pela caridade, amar a Deus, que é o bem comum de todos". No mesmo artigo, Tomás define que Deus é tanto a fonte quanto o princípio comum da bem-aventurança. Ao perguntar se o amor de caridade se limita a Deus ou se estende também ao próximo, Tomás é enfático: “amamos todos os próximos com o mesmo amor de caridade, enquanto eles se referem a este bem comum, que é Deus". (MARITAIN, 1947. p. 444).

Na Suma Teológica, Tomás de Aquino escreve que o bem comum é essencial, então, para esta vida social humana: "não poderia haver uma vida social de muitos, a não ser que alguém presidisse, tendo a intenção do bem comum". Ao tratar da diversidade das leis, reafirma que "[as leis servem à] utilidade do bem comum, que é necessário para a convivência humana". Em uma Questão específica sobre "a essência da lei”, pergunta se a lei ordena-se sempre ao bem comum e responde que sim, atentando para o fato de que "é necessário que a lei propriamente vise a ordem para a felicidade comum" ". (MARITAIN, 1947. p. 447. ).

Esta compreensão emanada da religião, e aceita universalmente, pode ser considerada hegemônica, uma vez que toda pessoa que se designe católica, deverá possuir e 
difundir esta noção de caridade e bem comum, a qual é bíblica, fonte inspirador para a Suma Teológica de Tomás de Aquino. Entretanto, guarda relação a questão da caridade com a tutela do mínimo existencial, uma vez que ambas possuem o foco naquele indivíduo que não possui a dignidade mínima para a sobrevivência humana.

\section{4 - Influencias na teoria do mínimo existencial em prol de uma tutela efetiva}

A tutela efetiva do mínimo existencial não compete somente a um determinado juiz, mas essencialmente à Administração Pública, a qual é detentora do numerário arrecadado dos impostos para a imediata efetivação de direitos ausentes, ou que deixaram de serem cumpridos.

Entretanto, os sistemas jurídicos, notadamente na esfera processual, ainda veem essencialmente vinculados à tutela do sujeito individual, a partir do momento, que ocorre uma provocação, devido à ausência da presença do mínimo existencial na realidade existente.

Nesse sentido, um exemplo que ocorreu no Rio de Janeiro, quando uma liminar em Ação civil pública, onde foi deferida pelo Juízo da Vara da Infância e Adolescência da Comarca de Queimados, condenando o Estado a contratar professores para o ensino fundamental visando suprir a insuficiência das turmas nas escolas públicas estaduais da região. Assim, é descrita:

AGRAVO DE INSTRUMENTO. TUTELA ANTECIPADA. VERBETE N. 59 DA SÚMULA DESTE TRIBUNAL. CONTRATAÇÃO DE PROFESSORES. ATUAÇÃO DO JUDICIÁRIO NA IMPLEMENTAÇÃO DE POLÍTICAS PÚBLICAS. [...] Direito à educação, erigido diretamente da Constituição Federal, que impõe a contratação de professores a fim de suprir a carência de material humano que acomete a rede de ensino fundamental e, indiretamente, obstaculiza a fruição do direito subjetivo fundamental. Desnecessidade de interposição legislativa. Inteligência dos arts. $5^{\circ} \S 1^{\circ}$ e $2^{\circ}, 6^{\circ}, 205$ e 208 , inciso I e $\$ 1^{\circ}$, da Lei Maior. Aplicabilidade imediata das normas definidoras de direitos fundamentais, que não se compadece com a alegação de ausência de fonte de custeio. A reserva do possível não pode servir de escusa ao descumprimento de mandamento fundado em sede constitucional, notadamente quando acarretar a supressão de direitos fundamentais, em atenção ao mínimo existencial e ao postulado da dignidade da pessoa humana. (RIO DE JANEIRO, 2008).

Sendo o ensino fundamental enquanto componente do mínimo existencial é objeto de proteção pelo texto constitucional, a ausência de professores para disciplinas específicas 
importa em violação da Constituição. A simples existência da escola e possibilidade de matrícula do aluno não atinge a finalidade constitucional em toda sua plenitude, porquanto o objetivo é possibilitar que as crianças tenham acesso ao conhecimento. (FONTE, 2013, p. 229).

Um ideal não tutelado pelo ente público, primeiro responsável para a sua efetivação, sendo perceptível o emprego da hegemonia de algum interesse diverso naquele que buscaria o maior bem comum a população local envolvida nesta situação. Sendo o ente público detentor de plenas condições da realização destas ações em prol da tutela do mínimo existencial, por que elas não ocorrem?

Por outro lado, para o exercício de suas liberdades, é indispensável ao indivíduo o atendimento pelo Estado das condições mínimas que possam lhe assegurar uma vida digna. Afigura-se, portanto, um ciclo virtuoso: o Estado exerce o seu poder de polícia tributário, interferindo na liberdade individual do cidadão, que contribui, por força daquele poder, para que o Estado obtenha os recursos necessários para o atendimento das condições primárias daquele indivíduo, sem as quais não pode exercer a sua própria liberdade. Tudo isso sem olvidar que o poder estatal não nasceu do nada, mas também do resultado do exercício pelo cidadão de sua liberdade política.

Considera-se o tributo como um dever fundamental, materializado por uma prestação pecuniária, delimitado pelas liberdades fundamentais e pelos princípios constitucionais gerais e específicos, com a finalidade de obter receitas, exigindo de quem realize o fato descrito na norma, elaborada nos termos da competência específica outorgada pela Constituição (TORRES, 2006, p. 371).

É clara a presença hegemônica do Estado, em todas as esferas sobre o cidadão, no tocante a obrigação de contribuição pecuniária.

O dever fundamental nasce do pacto constitucional e se diferencia dos demais deveres ali consagrados, em razão de se materializar por meio de prestação pecuniária ou outro valor que se possa transformar em dinheiro (artigo $3^{\circ}$ do Código Tributário Nacional, Lei $\left.n^{\circ} 5.172 / 1966\right)$.

A tutela jurídica ao mínimo existencial, gera distorções e mais problemas. Não que ela não deve ser utilizada, mas este ativismo judicial, não corrobora com a noção de bem comum e equidade distributiva. Não seria possível criar uma lei que emanasse de ações 
judicias, tendo em vista ela já existir, somente não ser tutelada pelo ente público em suas obrigações positivas.

A simples referência a algumas situações concretas vivenciadas na realidade prática é suficiente para demonstrar essa afirmação. O Município de Campinas gastou em 2009 o valor de $\mathrm{R} \$ 2.505 .762,00$ com o pagamento de condenações judiciais de fornecimento de medicamentos, para atender as 86 ações propostas naquele ano, beneficiando com isso 253 pacientes. Assim Finatti exemplifica e fundamenta com dados tal situação:

A totalidade de recursos municipais dispensados com medicamentos para atender aos usuários do Sistema Único de Saúde foi de R\$16.929.316,29.151 Considerando o número de habitantes do Município, os dados demonstram que quase $16 \%$ do orçamento municipal reservado para cobrir os custos com medicamentos foram empregados para atender apenas $0,023 \%$ da população que ingressou com medidas judiciais. Situação similar ocorreu no Estado de Minas Gerais em 2010. Dos $\mathrm{R} \$ 360.029 .986,11$ despendidos com fornecimento de medicamentos básicos e de alto custo pelo Estado, o valor de $\mathrm{R} \$ 55.052 .215,84$ foi destinado ao cumprimento de decisões judiciais dessa natureza, beneficiando um total de 4.762 pacientes em um Estado com 19.595.309 habitantes. Significa que somente 0,024\% dos cidadãos do Estado, que manejaram ações judiciais para garantir o acesso a esses bens, abocanharam aproximadamente $15,3 \%$ do total orçamentário gasto com distribuição de medicamentos. (FINATTI, 2010).

O tamanho da disparidade na distribuição dos valores, não admite a comparação com o bem comum, tendo em vista o bem individual, em atitude narcisista apropriar-se de parte significativa do valor arrecadado de todos, através de impostos e distribuído de maneira direcionada. A hegemonia de uma vontade geral, passa a ser a vontade individual, realizando o desmonte de um plano de atendimento universalizado, como é a saúde no Brasil.

O mínimo existencial, pode não ter sido tutelado a outros cidadãos, ou estes receberam valores além do mínimo para a sua sobrevivência. Entretanto, toda tutela estatal, ocorre a partir da tributação, ou da isenção do mesmo, como nas faixas de contribuição do imposto de renda.

O tributo se caracteriza como uma das formas de ingresso público, no quadro das receitas derivadas e oriundas de contribuições compulsórias. Sua exigência se dá através do ato de império do Estado, ao mesmo tempo em que configura um dos aspectos da cidadania, o dever de contribuir para os gastos públicos. Mais que a característica pecuniária da prestação e da sua compulsoriedade, outro traço substancial do dever de pagar tributos é a estreita 
relação com a legalidade de sua instituição. O tributo pode ser "opressão da liberdade, se o não contiver a legalidade". (TORRES, 2005a, p. 4).

No plano da dimensão bilateral da cidadania, Torres (2009, p. 154 e 155) percebe a confusão entre direitos e deveres quando o sistema se refere ao mínimo existencial e aos direitos sociais e econômicos. O financiamento para garantir a cidadania ocorre através da arrecadação e impostos ou da contribuição dos próprios titulares. Através de impostos, a incidência ocorre sobre todos os cidadãos e o financiamento para a prestação de serviços gratuitos será somente para alguns. Quanto ao sistema securitário, onde o próprio titular financia o seu direito, (INSS), a contribuição é com efeito piramidal, enquanto alguns contribuem outros são beneficiados, ocorrendo um ciclo. Para melhor compreensão entre o mínimo existencial e os direitos, temos o seguinte entendimento:

O primeiro (imposto), deve ser reservado ao mínimo existencial; o contributivo, aos direitos sociais e econômicos. Ambos os sistemas se apoiam na solidariedade, tomada, entretanto, em sentidos diferentes. Mas no Brasil, houve o emburilhamento dos dois modelos, máxime na questão da saúde, entendendo-se a gratuidade e a universalidade do sistema financiado pelos impostos, destinado ao mínimo existencial ( medicina preventiva, atendimento de urgência, campanhas de vacinação), a todas as prestações de saúde, com a criação do anômalo sistema único de saúde (SUS), que não tem paralelo de monta no direito comparado e que se financia pelas exóticas contribuições sociais sobre o faturamento e o lucro (196, I CF) e por outras contribuições, que repercutem sobre terceiros não titulares dos correlativos direitos às proteções estatais, o que inegavelmente as transforma em impostos com destinação especial. (TORRES, 2009, p. 155).

É perceptível a preocupação do autor com o SUS, o qual do ponto de vista do mínimo existencial, e do direito comparado, bem como do idealismo, sua origem é perfeita, buscando uma equidade total na igualdade. Entretanto, as anomalias acimas expostas, deterioram a mens inicial do bem comum existente no plano ideal.

A vertente negativa do mínimo existencial se caracteriza pela liberdade de ação ou omissão do indivíduo, sem qualquer constrangimento por parte do poder estatal. Traduz-se por meio de imunidades frente à cobrança de tributos, sejam eles impostos, taxas ou contribuições. A imposição por parte do poder público de qualquer ônus no exercício das liberdades, concernentes ao mínimo existencial, reveste-se de inconstitucionalidade, mesmo que o reconhecimento do direito emane de uma disposição infraconstitucional, pois, o que verdadeiramente caracteriza a imunidade não é a fonte formal e imediata de que promana, mas a circunstância de ser um fundamento pré-constitucional (TORRES, 2005a, p. 190). 
Mas, não é uma lei qualquer o instrumento do poder tributário, mas aquela emanada de quem detém, constitucionalmente, a competência para instituir e administrar. Tributo sem lei não é tributo, assim como também não o é a sanção de ato ilícito. Esta é penalidade por descumprimento de dever, mas não um dever fundamental, posto que limitada pela liberdade individual (TORRES, 2007, p. 45).

No cenário geral dos direitos fundamentais, de forma absoluta ou não, a depender da modalidade tributária, algumas liberdades recebem imunização diante do poder fiscal. Aqui interessa a imunidade relativa ao mínimo existencial, que, na realidade, trata-se das condições iniciais da liberdade, que não podem ser objeto de ingerência estatal sob nenhuma das modalidades dos tributos e, ainda, imprescindem das prestações positivas. Aquelas condições são marcadas por uma pré-existência constitucional, cujo entendimento perpassa pela identificação de um vínculo de respeito do ato de tributar para com os direitos humanos.

Nesta seara da tributação, parte-se do pressuposto estabelecido de que o Estado existe em função da pessoa e não o contrário. Em assim sendo, a administração pública deve pautar-se através de ações que visam ao cumprimento dos fins para os quais foi criada, com observância dos valores consagrados pelos direitos humanos e fundamentalizados no texto constitucional.

O poder de tributar dos Estados encontra limitação nos direitos fundamentais, ou seja, direta ou indiretamente, a tributação está sob as amarras daqueles direitos, instrumentalizados por meio dos princípios constitucionais. Com a superação do modelo positivista na segunda metade do século XX e com a aproximação da ética com o direito, foi possível transmigrar, para os Direitos Financeiro e Tributário, uma coletânea de valores, até então não concebida dentro daqueles ramos do Direito. A abertura sistêmica principiológica, feição da vigente Carta Magna, implica que o orçamento e a tributação transitem pelo cenário axiológico dos valores éticos e jurídicos.

O direito positivo não mais pode ser dissociado da ética. A ideia de justiça permeia a Constituição Brasileira, uma vez que essa expressamente propugna por uma "sociedade livre, justa e solidária". A ordem tributária brasileira compõe-se de um sistema normatizadamente estruturado, onde nele se pode encontrar a equalização das questões, dentro mesmo da estrutura sistematizada. (NOGUEIRA, 1995, p. 39).

A relação da capacidade contributiva com o mínimo existencial é de exclusão, ou seja, ela não está onde aquele se encontra. Devem ser identificadas, primeiro, as condições 
necessárias para uma vida digna, o seu conteúdo qualitativo, as margens de sua segurança e a sua realização. Somente após, encontra-se o Estado autorizado a intervir, por meio da atuação tributária. Dessa forma, o mínimo existencial pode ser encontrado na faixa de incapacidade contributiva, região onde não há qualquer revelação de riqueza justificadora da imposição tributária.

Com base nos direitos fundamentais e nas suas garantias de efetivação, pode-se afirmar que é urgente a necessidade de se reestruturar o sistema tributário, em bases arrecadatórias mais justas, com o fim de se eliminar a ingerência tributária ilegítima na esfera da liberdade do cidadão, da mesma forma como é indispensável à aplicação prioritária do dinheiro público no atendimento das carências mínimas relacionadas à vida digna. Não há outra maneira de se atender e tutelar ao mínimo existencial, senão através do respeito aos seus aspectos negativos e positivos.

\section{CONSIDERACÕES FINAIS}

Ao finalizar o presente estudo acerca do mínimo existencial e a hegemonia, tendo como preocupação a garantia do futuro destes direitos, é mister enfatizar que o objetivo principal foi investigar as matrizes filosóficas hegemônicas do historicismo e do idealismo, bem como uma breve pesquisa sobre o tema do bem comum abordado por Santo Tomas de Aquino, e confrontando-as com a teoria do mínimo existencial e as ações que tutelam o mesmo. Demonstrar comparativamente a influência da matriz filosófica hegemônica nas decisões que levam a garantia do bem tutelado no mínimo existencial, bem como sua eficiência e eficácia. Chega-se a um nível de aprofundamento satisfatório, haja vista as múltiplas variáveis que existem, devido à complexidade da própria sociedade.

É relevante frisar que a pesquisa, mesmo sendo tão somente teórica, não considerou a existência de um sujeito abstrato, mas sim de um sujeito de carne e osso, que sente a dor da ausência de condições materiais para a vida digna. No entendimento de Peces Barba (1999, p. 182), a finalidade última dos direitos fundamentais é "garantir a igualdade mínima", que o cidadão tenha a universalização do acesso ao que mais se faz necessário para a dignidade humana.

Entretanto, apesar das garantias serem plausíveis, para a perfeita efetivação e continuidade no tempo, faltam esforços e atitudes políticas, bem como o gerenciamento de recursos para os investimentos em programas e projetos para a sua viabilidade. $\mathrm{O}$ bem 
comum, a caridade ou o mínimo existencial, abordado ao longo do estudo, perde-se a partir de decisões judiciais que contemplam apenas interesses individuais, deixando assim, de ser bom para todos, mas apenas para aqueles que tem condições de buscar através da via judicial, a garantia de seu quinhão.

Entretanto, há escassez de recursos públicos, e no entendimento de para Paul Singer (2003, p. 254), o problema reside na ascensão da doutrina neoliberal, caso da hegemonia, a qual tem os direitos sociais como inimigo do sistema. Na medida em que o Estado é paternalista, novas exigências surgem da sociedade, transformando-o no "polvo de mil tentáculos", no dizer de Bobbio (2011, p. 144) em O Futuro da democracia. Este Estado gigantesco acaba não conseguindo atender às demandas, ficando também sujeito à corrupção e desvios de dinheiro cada vez maiores, eclodindo em crise e na opressão de direitos.

A hegemonia tem também uma função educativa devendo ser não só a forma na qual afirmar a direção, o poder de uma classe, de um bloco social, mas deve ser também o terreno e o instrumento para realizar a superação da subalternidade, para atingir uma nova, mais alta unificação entre governantes e governados, entre dirigentes e dirigidos.

Ante as proposições dos autores pesquisados, conclui-se que, essencialmente, a hegemonia tanto histórica jurídica como a idealista, possuem espaço na seara jurídica para buscar meios de desenvolvimento de uma nação. Entretanto, o seu isolamento ou exclusividade não dão conta de tutelar o mínimo existencial, em nações que dele necessitam. Aqui é claro, o entendimento do mínimo existencial, como aquela porção mínima para a sobrevivência humana, ante a linha da miséria. Logo em nações de suporto econômico favorável, não irão preocupar-se em tutelar este mínimo, uma vez que todos os possuem. 


\section{REFERÊNCIAS}

BARCELLOS, Ana Paula de. A eficácia jurídica dos princípios constitucionais: o princípio da dignidade da pessoa humana. Rio de Janeiro: Renovar, 2002.

BOBBIO Norberto. Liberalismo e democracia. Tradução Marco Aurélio Nogueira. 6. ed. São Paulo: Brasiliense, 2000. v. 1.

BOBBIO, Norberto. O futuro da democracia: uma defesa das regras do jogo. Tradução Marco Aurélio Nogueira. 12. ed. Rio de Janeiro: Paz e Terra, 2011.

BRASIL. Constituição da República Federativa do Brasil, 05 out. 1988. Diário da República Federativa do Brasil, 06 out. 1988. Disponível em: < http://www.planalto.gov.br/ccivil 03/Constituição/Constituição.htm >. Acesso em: 20 Jan. 2018.

CERRONI, Umberto. Lessico gramsciano. Roma: Riuniti, 1978.

COMPARATO, Fábio Konder. A afirmação histórica dos direitos humanos. 5. ed. São Paulo: Saraiva, 2007.

COUTINHO, Carlos Nelson. Atualidade de Gramsci. 1997 Disponível em: < http://www.acessa.com/gramsci/?page=visualizar\&id=293 > Acesso em: 12/01/2018.

FACHIN, Luiz Edson. Estatuto jurídico do patrimônio mínimo. 2. ed. Rio de Janeiro: Renovar, 2006.

FONTE, Felipe de Melo. Políticas Públicas e Direitos Fundamentais. São Paulo: Saraiva, 2013.

FERREIRA, Aurélio Buarque de Holanda. Novo dicionário da língua portuguesa. 3.ed. Curitiba: Positivo, 2004.

FINATTI, Deise Barbieri; VECHINI, Priscila Garbin. O perfil dos gastos destinados ao cumprimento de determinações judiciais no Município de Campinas. In: XXIV Congresso de Secretários Municipais de Saúde do Estado de São Paulo, 2010, Campinas - SP. Disponível em: < http://2009.campinas.sp.gov.br/saude/ biblioteca/XXIV_Congresso_de_Secretarios_Municipais_de_Saude_do_Estad o_SP/Complexidadedaatencaobasica/O_Perfil_dos_gastos_Deise.pdf >. Acesso: 15 jan. 2018.

FROELICH, Gregory. "On the Common Goods". The Aquinas Review, v. 15, 2008, .

Disponível em: .< http://ldataworks.com/aqr/FroelichOnTheCommonGoodsLarge Print.pdf > Acesso: 10. Fev. 2018.

GOYARD-FABRE, Simone. La philosophie du droit de Montesquieu. Paris: Libraire C. Klincksieck, 1973.

GRAMSCI, Antônio. Cadernos do Cárcere. Trad. Carlos Nelson Coutinho; - Rio de Janeiro: Civilização Brasileira, 2000.

GRUPENMACHER, Betina Treiger. Justiça fiscal e mínimo existencial. In: PIRES, Adilson Rodrigues; TÔRRES, Heleno Taveira (Org.). Princípios de direito financeiro e tributário: estudos em homenagem ao professor Ricardo Lobo Torres. Rio de Janeiro: Renovar, 2006. p. 99-114.

GRUPPI, Luciano. O conceito de hegemonia em Gramsci. Rio de Janeiro, Graal, 1978. 
JAPIASSÚ, Hilton e MARCONDES, Danilo. Dicionário Básico de Filosofia. 5.ed. Rio de Janeiro: Zahar, 2008

KANT, Immanuel. Fundamentação da metafisica dos costumes. Trad. Guido Antonio de Almeida. São Paulo: discurso Editorial Bacarolla, 2009

LEWIS, V. Bradley. The common good in classical political philosophy. Current Issues in Catholic Higher Education, v. 25, n. 1, winter/2006, p. 11-12. Disponível em: . faculty.cua.edu/lewisb/Common\%20Good3.pdf >. Acesso: 19 Jan. 2018.

MURPHY, Mark. Consent, Custom, and the Common Good in Aquinas's Account of Political Authority. The review of politics, v. 59, n. 2, 1997.

MARITAIN, Jacques. The Person and the Common Good. Trad. John J. Fitzgerald. The Review of Politics, v.8, n.4, 1947. pp. 419-55.

NOGUEIRA, Ruy Barbosa. Curso de direito tributário. 14. ed. São Paulo: Saraiva, 1995.

ORGANIZAÇÃO DAS NAÇÕES UNIDAS (ONU). Declaração Universal dos Direitos Humanos. . [S.1.], 1789. Disponível em; < http://www.onu.org.br/conheca-a-onu/documentos $>$.Acesso em: 05 ago. 2017.

PECES-BARBA MARTÍNEZ, Gregorio. Los derechos econômicos, sociales y culturales: su génesis y su concepto. Derechos y Liberdad. - Revista del Instituto Bartolomé de las Casas, 1999.

RAWLS, John. Uma teoria da justiça. São Paulo: Martins Fontes, 2002.

RIO DE JANEIRO. Tribunal de Justiça. Agravo de Instrumento n. 2007.00232900. Voto do Rel. Des. Carlos Eduardo Passos, Rio de Janeiro-RJ. D.J. 19-03-2008. Disponível em: < http:॥www.tj.rj.gov.br > Acesso em: 05 jan. 2018.

SARLET, Ingo Wolfgang. A eficácia dos direitos fundamentais. $7^{\text {a }}$. ed. rev., atual. e ampl. Porto Alegre: Livraria do Advogado, 2007.

SARMENTO, Daniel. A ponderação de interesses na constituição federal. 1. ed. Rio de Janeiro: Lumen Júris, 2002.

STRECK, Lenio Luiz. Jurisdição constitucional e decisão jurídica. 3. ed. São Paulo: Revista dos Tribunais, 2013.

TORRES, Ricardo Lobo. A cidadania multidimensional na era dos direitos. In: (Org.).

Teoria dos Direitos Fundamentais. 2. ed. Rio de Janeiro: Renovar, 2001, p. 243-342.

TORRES, Ricardo Lobo. Tratado de direito constitucional financeiro e tributário - Os direitos humanos e a tributação: imunidades e isonomia. 3. ed. rev. e atual. Rio de Janeiro: Renovar, 2005a.

TORRES, Ricardo Lobo. Curso de direito financeiro e tributário. 13.ed. Rio de Janeiro: Renovar, 2006.

TORRES, Ricardo Lobo. Tratado de direito financeiro e tributário: os tributos na constituição. Rio de Janeiro: Renovar. 2007.

TORRES, Ricardo Lobo. O direito ao mínimo existencial. Rio de Janeiro: Renovar, 2009.

VILELLA, Fabio Renato. Idealismo Filosófico. 2016. Disponível em :< www.fabiorenatovillela.com > Acesso: 10 jan. 2018 